\title{
Ash-covered forest is 'Permian Pompeii'
}

\section{Scientists reconstruct ancient ecosystem from plants preserved in volcanic eruption.}

\section{Sid Perkins}

20 February 2012

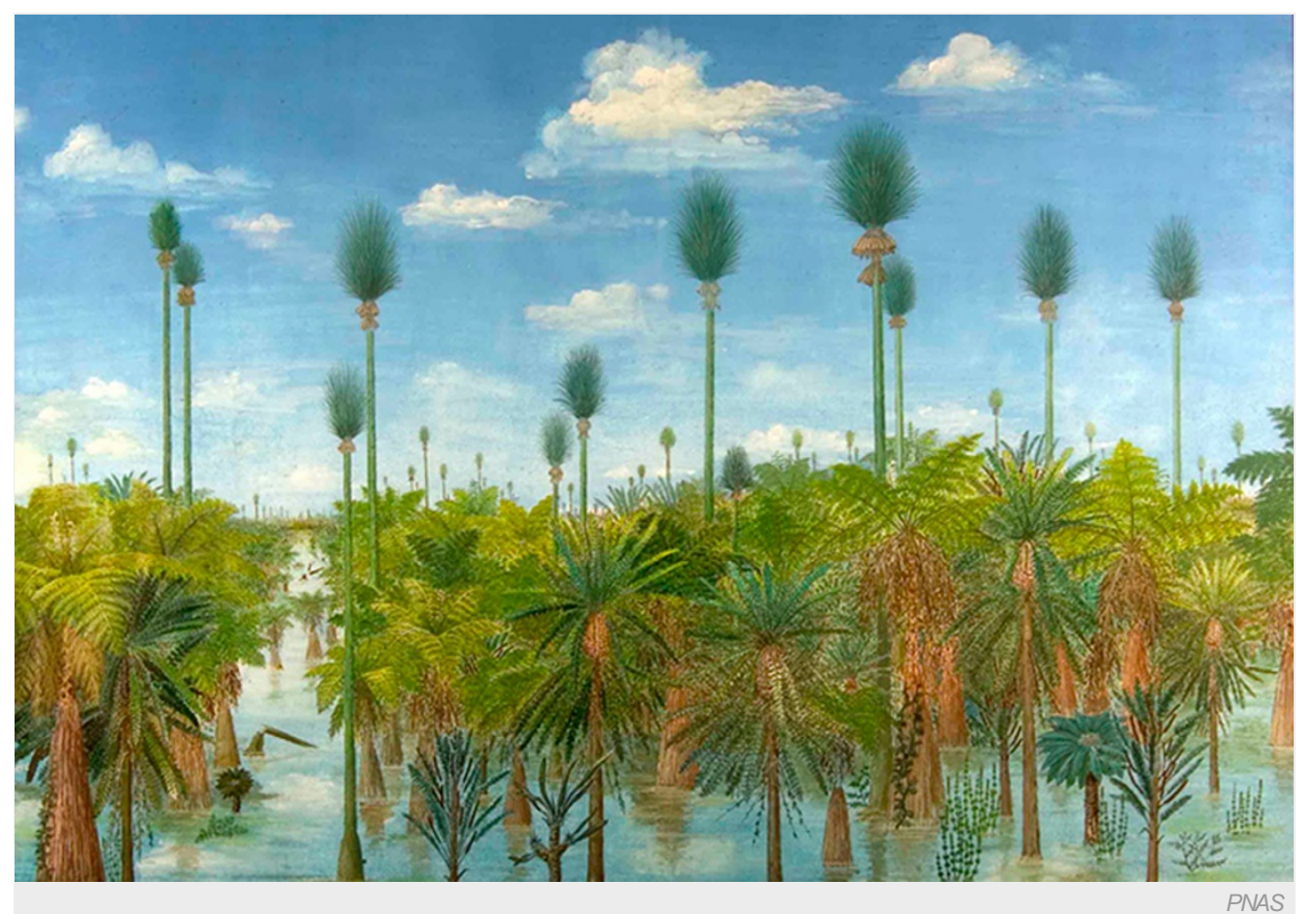

An artist's impression of a 300-million-year-old peat forest in northern China, based on plant fossils preserved in a huge volcanic ash-fall.

An ancient swampy forest full of long-extinct plant species has been brought to life through analyses of well-preserved fossils entombed in a layer of volcanic ash. Although many of the species are already known to science, the eruption that smothered the tropical forest in what is now northern China created a time capsule that reveals an almost unprecedented level of detail about the region's flora, scientists say.

Palaeoecologists can usually only infer the richness of an ancient forest ecosystem by piecing together fossils of plant fragments of varying ages. Only when broad areas are preserved in situ in a geological instant can researchers get a true picture of the composition and ecology of the forest, says Hermann Pfefferkorn, a palaeoecologist at the University of Pennsylvania in Philadelphia. Although floods can cover wide swathes of landscape with sediment in one fell swoop, they often bring in organisms from other areas and wash local inhabitants away. The most reliable preservation, Pfefferkorn suggests, comes from a smothering layer of volcanic ash.

Pfefferkorn and his colleagues have unearthed one such time capsule from 298-million-year-old rocks in northern China — a 'forest Pompeii' where the weight of falling ash ripped leaves from twigs, toppled trees and then buried the lot. The consistent thickness of ash deposits in the region, as well as the size of individual ash particles, suggest that the volcanic blast occurred more than 100 kilometres away.

\section{Forest of ferns}

The researchers reconstructed the ancient ecosystem by analysing the positions of individual plants across three sites that together cover more than 1,000 square metres. Species from six plant groups lived there, Pfefferkorn and his team report online today in the Proceedings of the National Academy of Sciences ${ }^{1}$. Besides sporting a broad, low canopy of tree ferns, the peat forest contained trees that looked like feather dusters, with trunks twice the height of telephone poles; vines and three species of an enigmatic group called Noeggerathiales - small spore-bearing trees that scientists think are close relatives of the earliest ferns. 
we knew from other places, but we had no idea that they actually grew together."

The team's findings "provide a view into the guts of a coal-forming swamp in its prime", says Scott Elrick, a geologist with the Illinois State Geological Survey in Champaign.

When the forest was alive, it sat on the northwestern edge of a large tropical island off the eastern shore of the supercontinent Pangaea, the researchers say. Most forests like this one had died out elsewhere millions of years earlier — their habitats had dried as landmasses comprising the supercontinent came together and the forests ended up farther from the coasts, says Ralph Taggart, a palaeoecologist at Michigan State University in East Lansing. In that sense, he notes, even before it was buried, this peat forest was already frozen in time as forests elsewhere evolved.

Nature I doi:10.1038/nature.2012.10061

\section{References}

1. Wang, J., Pfefferkorn, H. W., Zhang, Y. \& Feng, Z. Proc. Natl Acad. Sci. USA http://dx.doi.org/10.1073/pnas.1115076109 (2012). 